\title{
ПАМЯТИ ПРОФЕССОРА В.В. ВОЛКОВА
}

https://doi.org/10.17816/OV12189-93

\section{(C) А.Н. Куликов, В.А. Рейтузов, А.Ф. Соболев, Ю.А. Кириллов}

ФГБВОУ ВО «Военно-медицинская академия им. С.М. Кирова» Минобороны России, Санкт-Петербург

Для цитирования: Куликов А.Н., Рейтузов В.А., Соболев А.Ф., Кириллов Ю.А. Памяти профессора В.В. Волкова // Офтальмологические ведомости. - 2019. - Т. 12. - № 1. - С. 89-93. https://doi.org/10.17816/OV12189-93

४ Статья посвящена памяти Героя Социалистического Труда, лауреата Государственной премии СССР, заслуженного деятеля науки РСФСР, профессора В.В. Волкова. Авторы рассмотрели его жизненный путь, клиническую, научную и педагогическую деятельность.

Ключевые слова: офтальмология; кафедра офтальмологии; комбинированные поражения органа зрения; лазеры; глаукома; физиология органа зрения.

\section{IN MEMORY OF PROFESSOR V.V. VOLKOV}

\section{(C) A.N. Kulikov, V.A. Reytuzov, A.F. Sobolev, Yu.A. Kirillov}

S.M. Kirov Military Medical Academy, Saint Petersburg, Russia

For citation: Kulikov AN, Reytuzov VA, Sobolev AF, Kirillov YuA. In memory of professor V.V. Volkov. Ophthalmology Journal. 2019;12(1):89-93. https://doi.org/10.17816/OV12189-93

$\diamond$ The article is dedicated to the memory of Hero of Socialist Labor, the USSR State Prize Laureate, Honored Scientist of the RSFSR, Professor V.V. Volkov. The authors reviewed his life path, clinical, scientific, and educational activities.

Keywords: ophthalmology; Department of Ophthalmology; combined lesions of the organ of vision; lasers; glaucoma; physiology of the organ of vision.

21 февраля 2019 г. ушёл из жизни один из самых ярких, творчески одарённых представителей санкт-петербургской офтальмологической школы генерал-майор медицинской службы (1980), доктор медицинских наук (1964), профессор (1965), заслуженный деятель науки РСФСР (1975), Герой Социалистического Труда (1982), лауреат Государственной премии СССР (1986), почётный доктор Военно-медицинской академии (2006), начальник кафедры офтальмологии Военномедицинской академии, главный офтальмолог Министерства обороны СССР (1967-1989) Вениамин Васильевич Волков.

Большая часть его творческой жизни была тесно связана с кафедрой офтальмологии Военно-медицинской академии им. С.М. Кирова, где он плодотворно трудился более 60 лет.

Вениамин Васильевич родился 20.01.1921 в Ташкенте. В 1938 г. окончил с золотым аттестатом специальную (артиллерийскую) среднюю школу в Ленинграде и поступил в Военно-медицинскую академию. Был сталинским стипендиатом. В 1941 г. в блокадном Ленинграде после обучения выполнял обязанности бойца истребительного батальона, обезвреживал зажигательные бомбы. Награждён медалью «За оборону Ленинграда».

По окончании Военно-медицинской академии в 1942 г., дислоцировавшейся в то время в Самарканде, В.В. Волков был направлен на Сталинградский фронт, в 34-ю гвардейскую стрелковую дивизию, в рядах которой он прошёл всю войну. В.В. Волков принимал участие в одном из крупнейших сражений Второй мировой войны: вначале в сдерживании прорывавшихся с Северного Қавказа к Астрахани немецко-фашистских войск, а потом и в окружении Сталинградской группировки противника.

В.В. Волков участвовал в освобождении Ростова-на-Дону (награждён орденом Крас- 


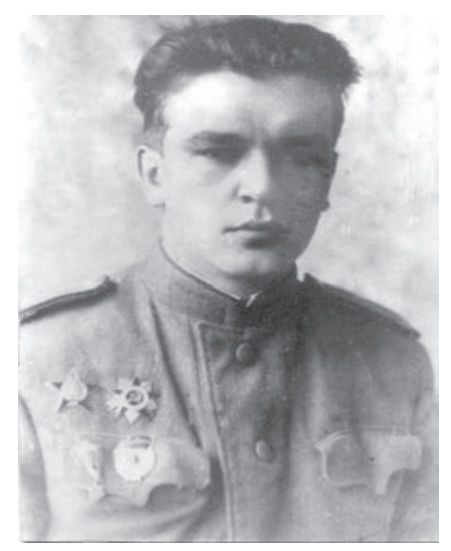

Pис. 1. В.В. Волков, командир медико-санитарного батальона 34-й гвардейской стрелковой дивизии, 1945

Fig. 1. V.V. Volkov, the commander of the medical battalion of the $34^{\text {th }}$ Guards Rifle Division, 1945

ной Звезды), Украины, Молдавии, Румынии, Болгарии, Югославии, Венгрии и Австрии.

В 1948 г. после окончания лечебно-профилактического факультета он был оставлен в клинике глазных болезней Военно-медицинской академии. На кафедре, возглавляемой профессором Б.Л. Поляком, В.В. Волков прошёл все ступени врачебной и научной деятельности - от старшего ординатора клиники до заместителя начальника кафедры, сформировался как великолепный клиницист и уже известный учёный в области поражений органа зрения, его физиологии.

В 1967 г. профессор В.В. Волков возглавил кафедру офтальмологии. Он не только сохранил лучшие традиции научной школы первой в России кафедры офтальмологии, но и существенно развил и углубил их.

Проблеме радиационного поражения глаз посвящены многолетние личные исследования профессора В.В. Волкова, которые завершились защитой докторской диссертации (1965) и выходом монографии «Бета-лучевые повреждения» (1970). В работах В.В. Волкова и его учеников О.Н. Нестеренко (1970), Э.Ф. Ярославцева (1974) и Н.В. Сухопары (1975), Ю.В. Гайдая (1989), О.А. Марченко (1995-1999) - и др. показаны возможности эффективного использования радиоактивных изотопов для диагностики и лечения новообразований органа зрения.

На кафедре офтальмологии традиционно уделялось большое внимание изучению проблемы ожогов глаз (Ушаков Н.А., 1972; Даниличев В.Ф., 1973; Тер-Андриасов Э.Л., 1976; Трояновский Р.Л., 1976). В 1972 г. В.В. Волков разработал классификацию ожогов органа зрения, которая и сегодня используется военными офтальмологами. За внедрение оперативных способов лечения в реабилитации больных с последствиями тяжёлых ожогов глаз по представлению В.В. Волкова в 1984 г. сотруднику кафедры профессору Н.А. Ушакову была присуждена Государственная премия СССР.

Многолетние исследования сотрудников кафедры по комбинированному поражению глаз были обобщены в монографии В.В. Волкова и В.Г. Шиляева «Комбинированные поражения глаз» (1976), которая в 1979 г. была удостоена премии АМН СССР им. академика В.П. Филатова.

В период 1979-1989 гг. с учётом опыта работы в Афганистане (Б.В. Монахова, М.М. Дронова, В.Ф. Даниличева, Р.Л. Трояновского, А.Ф. Гацу) под руководством В.В. Волкова были разработаны основные принципы современной хирургической обработки тяжёлых травм глаза. В настоящее время концепция проведения раннего витреального вмешательства является ведущей на кафедре офтальмологии. На международных конгрессах по травме глаза в Шопроне (Венгрия, 2003), Риме (Италия, 2006), Вюрцбурге (Германия, 2008) и на IX съезде офтальмологов России (Москва, 2010) профессора В.В. Волков и Э.В. Бойко внесли предложения по совершенствованию международной классификации открытой травмы глаза. Результаты своих многолетних исследований были обобщены в монографии «Открытая травма глаза», которую профессор В.В. Волков издал в 2016 г. к своему 95-летию.

Широко известны работы профессора В.В. Волкова и его школы, посвящённые вопросам физиологии зрения и физиологической оптики. Сотрудники и ученики профессора В.В. Волкова изучали проблемы миопии и военной службы (Якимов Б.Л., 1970), аккомодации (Колесникова Л.Н., 1973; Мяло Н.М., 1985), цветового и сумеречного зрения (Сергиенко В.И., Гайдай В.М., 1974; Николаенко В.П., 1994), офтальмоэргономики (Парпаров А.Б., 1976; Грос Андор, 1988), действия на глаз интенсивных световых раздражителей (Балашевич А.И., 1974; Товкач В.И., 1980; Преображенский П.В., 1986; Марков Ц., 1989), электрофизиологии (Черныш В.Ф., 1982; Сосновский В.В., 1990), методы коррекции астигматизма (Кривенкова Н.А., 1972; Кириллов Ю.А., 1976), очковой коррекции в противогазе (Михайлов А.И., Нестеренко О.Н., Сосновский В.В., 1979).

В 1988 г. под руководством профессора В.В. Волкова и доктора медицинских наук Ю.Е. Шелепина сотрудниками кафедры академии и Института физиологии Российской академии наук им. И.П. Павлова создан атлас по 


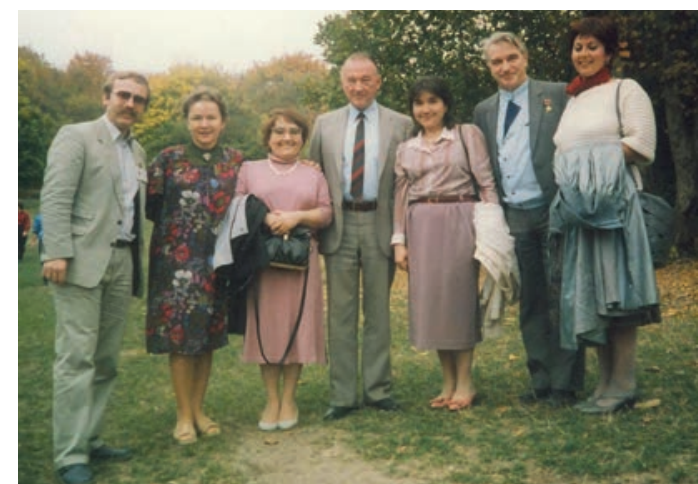

Рис. 2. В.В. Волков вместе с Х. Нойбауер (в центре) в Телави, начало 80-х гг.

Fig. 2. V.V. Volkov together with H. Neubauer (in the centre) in Telavi, the early ' 80 s

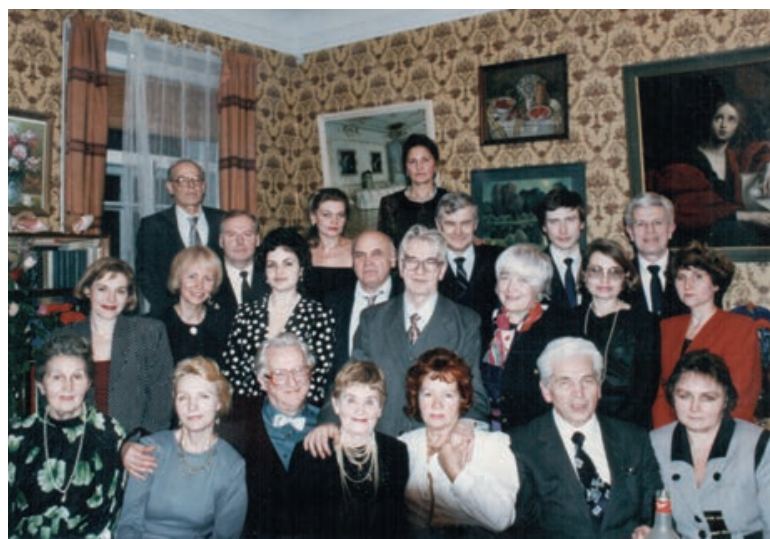

Pис. 4. Офтальмологи Санкт-Петербурга на юбилее В.В. Волкова, 1996

Fig. 4. The Ophthalmologists of St. Petersburg on the anniversary of V.V. Volkov, 1996

визоконтрастопериметрии. В 1993 г. при участии В.В. Волкова, В.А. Рослякова и В.П. Сергеева совместно с сотрудниками Всесоюзного научно-исследовательского института метрологии им. Д.И. Менделеева доктором технических наук Е.И. Юстовой и К.А. Алексеевой был разработан и внедрён в практику новый метод исследования цветового зрения с помощью пороговых таблиц. В 1999 г. совместно с профессором А.М. Шамшиновой издана монография «Функциональные методы исследования в офтальмологии», второе издание которой вышло в 2001 г.

Профессора В.В. Волков и Н.А. Ушаков являлись активными сторонниками внедрения в клиническую практику в нашей стране экстракапсулярной экстракции катаракты. Они создали и запатентовали собственную модель интраокулярной линзы, организовали производство этих линз в клинике офтальмологии Военно-медицинской академии. Эти линзы использовали в клинической практике вплоть до 90-х гг. ХХ в.

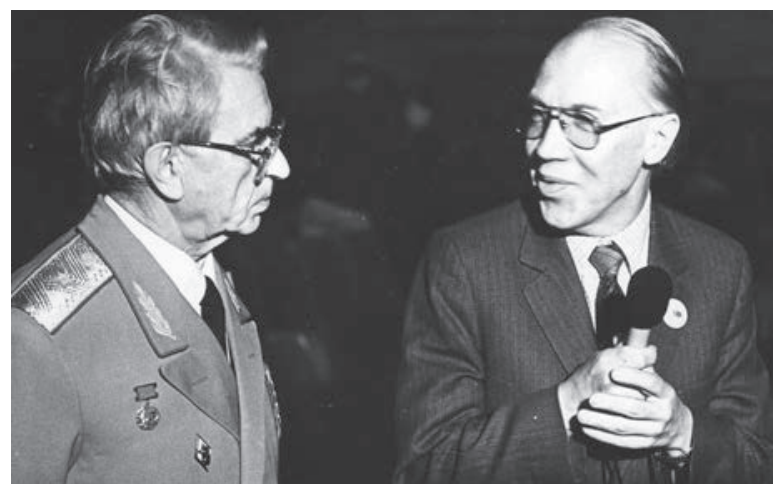

Pис. 3. В.В. Волков вместе вместе с академиком М.М. Красновым 80-е гг.

Fig. 3. V.V. Volkov together with academician M.M. Krasnov in the " $80 \mathrm{~s}$

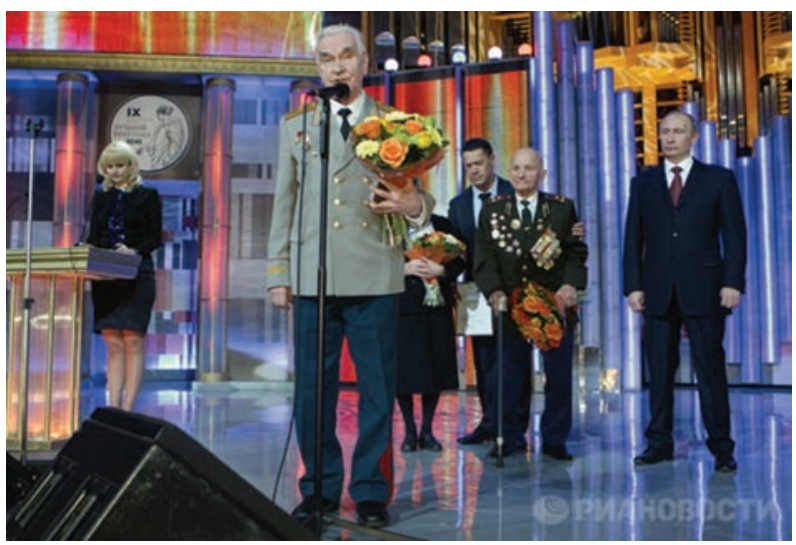

Pис. 5. Поздравление с присуждением звания «Лучший врач года», 2010

Fig. 5. Congratulation on the award of the title of "The Best Doctor of the Year", 2010

В 1983 г. по инициативе профессора В.В. Волкова была организована научно-исследовательская лаборатория контактной коррекции зрения, которую возглавил профессор Н.А. Ушаков. Созданные в лаборатории оригинальные мягкие контактные линзы апробировали сотрудники кафедры с бандажной целью и с целью создания пролонгированной лекарственной формы, в том числе в условиях боевых действий в Афганистане.

Возможности использования интраокулярных, мягких контактных линз, лакопротезов и других полимерных материалов в офтальмологии были рассмотрены в вышедшей в соавторстве монографии «Офтальмохирургия с использованием полимеров» (2004 г., второе издание в 2009 г.).

Проблемам пересадки склеры и роговицы, новым методам консервации тканей глаза посвящены диссертационные исследования Е.Е. Сомова (1973), М.М. Дронова (1987), Ф. Касухи (1977). В монографии «Криоконсервация и транспланта- 
ция роговицы» Т.Н. Юрченко, Т.М. Шарлай, В.В. Волкова, М.М. Дронова, О.В. Репко (1986) подытожен цикл работ по кератопластике и созданию банка тканей. За участие в разработке метода длительной криоконсервации роговицы В.В. Волков и М.М. Дронов в 1986 г. были удостоены Государственной премии СССР.

Существенный вклад внесла школа профессора В.В. Волкова в решение проблемы глаукомы. Результаты изучения роли гониоскопии и тонографии для оценки гидродинамики глаза представлены в исследовании В.С. Красновидова (1970), опыт лечения острого приступа глаукомы - в исследовании Е.Н. Индейкина (1971), изучение циркуляции жидкости в зрительном нерве - Р.И. Коровенкова (1978), оценка состояния диска зрительного нерва и зрительных функций при глаукоме - А.И. Журавлёва (1986), опыт лечения вторичной глаукомы - А.Ф. Юмагуловой (1981), изучение видеограммы и диска зрительного нерва при разных стадиях глаукомы до и после её оперативного лечения - И.Л. Симаковой (1997). В 2003-2009 гг. по предложению профессора В.В. Волкова И.Л. Симаковой совместно с учёными кафедры прикладной математики Санкт-Петербургского государственного политехнического университета впервые в России была разработана модификация новой технологии периметрии - периметрия с удвоением пространственной частоты. Результаты многолетних исследований обобщены в монографии В.В. Волкова, Л.Б. Сухининой, Е.И. Устиновой «Глаукома, преглаукома, офтальмогипертензия» (1985), удостоенной премии АМН СССР им. акад. М.И. Авербаха в 1989 г. Богатый клинический опыт и результаты фундаментальных исследований были обобщены в изданных профессором В.В. Волковым монографиях «Глаукома при псевдонормальном давлении» (2001) и «Глаукома открытоугольная» (2008).

Благодаря тесному сотрудничеству с Государственным оптическим институтом им. С.И. Вавилова на кафедре проводились пионерские работы по разработке и внедрению отечественных лазеров в клиническую практику (на волнах 1,06; 1,54; 1,96 мкм (Балашевич Л.И., 1980-1988; Гацу А.Ф., Березин Ю.Д., 1980; Кулаков Я.Л., 1986). А в 1991 г. В.В. Волков, А.Б. Качанов и С.Э. Гончаров первыми в нашей стране показали эффективность диодного лазера (длина волны - 0,81 мкм), созданного в лаборатории Ж.И. Алферова для транссклеральной циклокоагуляции при злокачественной глаукоме.
Фундаментальные и прикладные исследования учеников В.В. Волкова по различным клиническим проблемам представлены в диссертационных работах: по лечению травматических гифем и гемофтальмов (Краснов А.М., 1972; Данилов А.В., 1987), по иммунологии хронических конъюнктивитов и бельм (Семёнов Д.Н., 1973; Пирогов Ю.И., 1989), по биохимии глаза (Цвелева А.Г., 1973), физиологии и патологии слезоотведения (Султанов М.Ю., 1979; аль Шихаби, 1975; Бржеский В.В., 1990), флюоресцентной ангиографии (Пурескин Н.П., 1977), применению протеолитических ферментов при заболеваниях и повреждениях глаз (Даниличев В.Ф., 1983), сочетанной травме глазницы (Панина О.Л., 1986).

В 1990-1999 гг. профессор В.В. Волков возглавлял межотраслевую лабораторию клинических испытаний оптических приборов. Базой лаборатории служила клиническая глазная городская больница № 7 на ул. Моховой, 38. К научной работе В.В. Волков привлекал молодых перспективных сотрудников больницы: И.Л. Симакову, А.Б. Качанова, О. А. Марченко и др.

Профессор В.В. Волков активно внедрял в учебный процесс достижения офтальмологии тех лет, что нашло отражение в изданном в 1980 г. в соавторстве с профессором В.Г. Шиляевым учебнике для курсантов «Общая и военная офтальмология», а также в пособиях для слушателей ординатуры, изданных профессором В.В. Волковым совместно с профессорами А.И. Горбанем и О.А. Джалиашвили: «Клинические исследования глаза с помощью приборов» (1971), которое удостоено премии АМН СССР им. акад. М.И. Авербаха (1973), и «Клиническая визо - и рефрактометрия» (1976).

Профессор В.В. Волков воспитал целую плеяду учеников и последователей, многие из которых возглавили кафедральные коллективы и офтальмологические учреждения нашей страны, в их числе профессора В.Ф. Даниличев, Л.И. Балашевич, Э.В. Бойко, В.В. Бржеский, А.И. Журавлёв, А.Н. Куликов, И.Б. Максимов, В.П. Николаенко, Е.Е. Сомов, Р.Л. Трояновский, Н.А. Ушаков, М.М. Шишкин. Под руководством Вениамина Васильевича подготовлено 13 докторов и 47 кандидатов медицинских наук.

Профессор В.В. Волков активно занимался общественной деятельностью. Он действительный член Лазерной академии наук РФ (1996), Академии медико-технических наук РФ (1997). Почётный академик Российской академии естественных наук (2000). Почётный член офтальмологических об- 
ществ России, Болгарии и Кубы. Член международных обществ глаукоматологов, офтальмоонкологов и исследователей глаза. Почётный гражданин городов Зернограда (Россия, 1993) и Талмазы (Молдавия, 1985). Почётный член Всероссийского офтальмологического научного медицинского общества, председатель правления Санкт-Петербургского научного общества офтальмологов (1972-2009), член редколлегии журнала «Вестник офтальмологии» и редакционных советов «Военно-медицинского журнала» и «Офтальмохирургии».

В 1998 г. Американский биографический институт назвал его «Человеком года-98». В 2000 г. решением Қомитета по наименованию малых планет Солнечной системы Международного астрономического союза малой планете № 7555 присвоено имя Вен Волков, международным признанием стало награждение его Серебряной медалью Марии Кюри и бриллиантом Да Винчи.

Вениамин Васильевич Волков был интеллигентным, корректным, внимательным, доброжелательным человеком. Он всегда был доступен окружающим. Поражала его память. Часто он, увидев кого-нибудь, мог легко вспомнить событие 10-15-летней давности. Вениамин Васильевич обладал высокой работоспособностью. После операционного дня он работал над статьями, нередко до позднего вечера.

Прощаясь с В.В. Волковым, мы понимаем, что от нас ушла целая эпоха в офтальмологии. Светлая память о профессоре В.В. Волкове будет храниться в сердцах благодарных учеников и сотрудников.

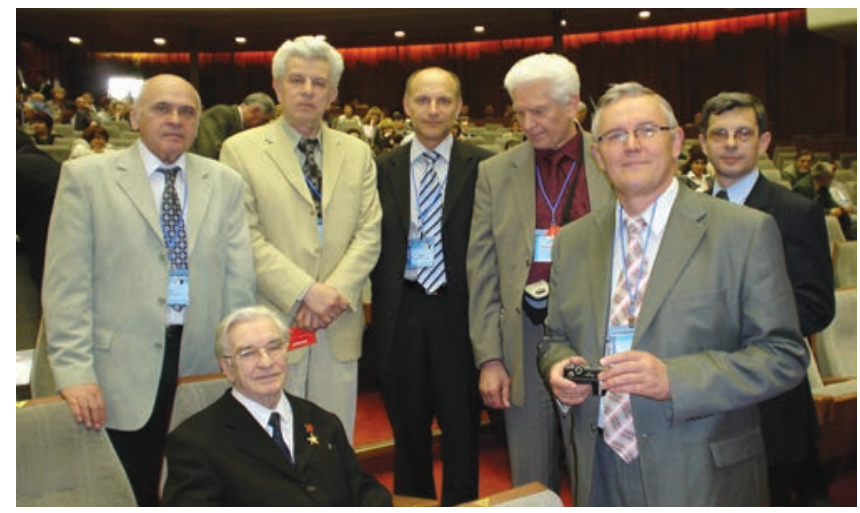

Рис. 6. В.В. Волков на конференции с учениками

Fig. 6. V.V. Volkov at the conference with students

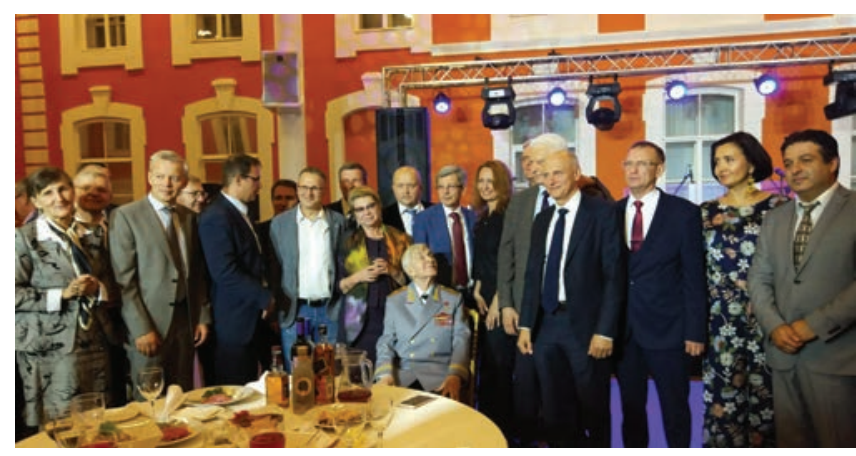

Pис. 7. В.В. Волков на юбилейной конференции, посвящённой 200 -летию кафедры офтальмологии ВМедА, 2018

Fig. 7. V.V. Volkov at the jubilee conference devoted to the $200^{\text {th }}$ anniversary of the Ophthalmology Department of the Military Medical Academy, 2018

Information about the authors

Алексей Николаевич Куликов - д-р мед. наук, доцент, начальник кафедры офтальмологии. ФГБВОУ ВО «Военно-медицинская академия им. С.М. Қирова» Министерства обороны Российской Федерации, Санкт-Петербург. E-mail: alexey. kulikov@mail.ru. SPIN: 6440-7706.

Владимир Алексеевич Рейтузов - канд. мед. наук, доцент, кафедра офтальмологии. ФГБВОУ ВО «Военно-медицинская академия им. С.М. Кирова» Министерства обороны Российской Федерации, Санкт-Петербург. E-mail: varvar.61@mail.ru.

Андрей Фёдорович Соболев - канд. мед. наук, старший преподаватель кафедры офтальмологии. ФГБВОУ ВО «Военно-медицинская академия им. С.М. Кирова» Министерства обороны Российской Федерации, Санкт-Петербург. E-mail: af_sobolev@mail.ru.

Юрий Алексеевич Кириллов - канд. мед. наук, доцент, кафедра офтальмологии. ФГБВОУ ВО «Военно-медицинская академия им. С.М. Қирова» Министерства обороны Российской Федерации, Санкт-Петербург. Head of the Department. Ophthalmology Department. S.M. Kirov Military Medical Academy, St. Petersburg, Russia. E-mail: alexey.kulikov@mail.ru. SPIN: 6440-7706.

Vladimir A. Reytusov - MD, PhD, assistant professor, Ophthalmology Department. S.M. Kirov Military Medical Academy, St. Petersburg, Russia. E-mail: varvar.61@mail.ru.

Andrey F. Sobolev - MD, PhD, Senior Lecturer. S.M. Kirov Military Medical Academy, St. Petersburg, Russia. E-mail: af_sobolev@mail.ru.

Yuriy A. Kirillov - канд. мед. наук, доцент, кафедра офтальмологии. S.M. Kirov Military Medical Academy, St. Petersburg, Russia.
Alexey N. Kulikov - MD, PhD, DMedSc, Professor, 